\title{
Implementing the Balanced Scorecard in Excel for Small and Medium Enterprises
}

\author{
A. Vieira ${ }^{1}$, N. Soares ${ }^{2}$, S. D. Sousa ${ }^{1}$ \\ ${ }^{1}$ ALGORITMI Research Centre/Department of Production and Systems, University of Minho, Braga, Portugal \\ ${ }^{2}$ Department of Information Systems, University of Minho, Guimarães, Portugal \\ ${ }^{1}\{$ antonio.vieira/sds\}@dps.uminho.pt \\ ${ }^{2}$ nuno.seraos@gmail.com
}

\begin{abstract}
Performance measurement is a way for organizations to be able to assess processes' performance. The Balanced Scorecard (BSC) is one of the best-known performance measurement systems. However, many small and medium enterprises (SME) face problems when trying to implement these frameworks, due to software associated costs. In this context, this paper documents the work conducted to develop a low cost solution for SME. The solution consisted on implementing the BSC in an excel workbook. The created tool allows users to have a chromatic view over data and assess its quality, by introducing risk analysis, through the utilization of trails with different intensities, depending on the associated risk. Moreover, data is automatically recorded to allow traceability and dynamic charts were introduced to allow the analysis of different performance attributes.
\end{abstract}

Keywords - Balanced Scorecard, MS Excel, Performance Measurement, Small and Medium Enterprises.

\section{INTRODUCTION}

In the global and competitive market, organizations face many complex challenges, in order to succeed. As such, organizations need to comply with a series of actions, such as: interact with different organizations towards a more flexible supply chain; accurately respond to customer and market needs; and have more flexible processes. Nonetheless all of this should be obtained efficiently, aiming costs reduction. To better respond to these challenges, companies need information related to their business processes, which should be updated, accurate, dynamic, integrated, accessible and visible, to enable a better decision-making [1].

Performance measurement is a way for organizations to measure the performance of their processes. According to Neely et al. [2], it is the process of quantifying action, where measurement is the process of quantification and action leads to performance. The authors further considered that performance measurement is the process of quantifying two other fundamental dimensions of performance: efficiency and effectiveness of action. The last dimension refers to the extent to which customer requirements are met, whereas the first refers to a measure of how economically the resources of a firm are used, when providing a given level of customer satisfaction. Considering these definitions, performance measurement can be defined as a metric used to quantify the efficiency and/or effectiveness of an action. In this regard, performance measurement systems (PMS) are used to quantify both the efficiency and effectiveness of actions.

Some PMS are one-dimensional, only analysing a dimension of the organization, e.g. financial or customer satisfaction dimensions. This is a very narrow vision of the problem and, as such, organizations should adopt a balanced approach that considers a set of dimensions [3].

Several performance measurement frameworks exist. However, the BSC, proposed by Kaplan and Norton [4], is one of the best known, which considers a multidimension perspective over four different areas of activity of an organization, namely: internal business process, customer, financial and innovation and learning. These dimensions represent a balance between financial and non-financial indicators, internal and external constituents of the organization and lag and lead indicators, which can be used to align the business activities to the vision and strategy of an organization [4]. These dimensions form a strategy map, which gives an organization a visual tool to explain cause and effects relationships between performance indicators (or between its associated objectives). By using it, executives and managers at different levels can monitor whether they are actually driving strategic success [5].

Several tools exist to implement the BSC in organizations. Some of which are software programs, which have high costs associated. These onerous solutions are many times only accessible for bigger organizations, because in many SME financial resources are scarce [6].

In this context, this paper documents the work conducted to develop a solution for implementing the BSC in SME, considering a low cost solution. The solution was implemented in Microsoft Excel. This solution was based on typical restrictions from SME [8].

The remaining document is organized as follows: the second section will present a literature review. The third section is dedicated to the discussion over the implemented features in the excel workbook. Lastly, the main conclusions will be discussed in the last section.

\section{LITERATURE REVIEW}

Designing a good performance measure involves more than just providing a formula. Other problems must be addressed, otherwise efficiency and effectiveness is not ensured. Table I shows an example of attributes that can be used to define a good performance measure. 
TABLE I

MAIN PERFORMANCE MEASURE ATTRIBUTES [9]

\begin{tabular}{|c|c|}
\hline Attribute & Description \\
\hline Name & $\begin{array}{l}\text { Effective names to avoid ambiguities. A } \\
\text { good name explains the meaning of the } \\
\text { measure and defines why it is important }\end{array}$ \\
\hline Objective/ purpose & $\begin{array}{l}\text { The relationship between the measure and } \\
\text { the objectives should be clear }\end{array}$ \\
\hline Scope & $\begin{array}{l}\text { Business areas or parts of the organisation } \\
\text { measured. }\end{array}$ \\
\hline Targets & $\begin{array}{l}\text { The objectives of the organisation to be } \\
\text { attained }\end{array}$ \\
\hline Formula calculation & $\begin{array}{l}\text { The precise calculation of the measure } \\
\text { should be known. This formula represents } \\
\text { the way in which the performance will be } \\
\text { measured }\end{array}$ \\
\hline Units of measurement & The units of measurement used \\
\hline $\begin{array}{l}\text { Frequency of } \\
\text { measurement }\end{array}$ & $\begin{array}{l}\text { The frequency of measurement recording } \\
\text { and report preparation. It is related to the } \\
\text { importance of the measure and the volume } \\
\text { of data available }\end{array}$ \\
\hline Frequency of review & $\begin{array}{l}\text { The frequency with which the measures } \\
\text { are reviewed }\end{array}$ \\
\hline Source of data & $\begin{array}{l}\text { The real source of data to calculate the } \\
\text { measure. This source has to be consistent }\end{array}$ \\
\hline $\begin{array}{l}\text { Person responsible } \\
\text { for the measurement }\end{array}$ & $\begin{array}{l}\text { Person in charge of collecting the data and } \\
\text { reporting the measure }\end{array}$ \\
\hline $\begin{array}{l}\text { Person responsible } \\
\text { for the measure }\end{array}$ & $\begin{array}{l}\text { Person in charge of achieving better } \\
\text { performance }\end{array}$ \\
\hline $\begin{array}{r}\text { Person responsible } \\
\text { for the data }\end{array}$ & $\begin{array}{l}\text { Person in charge of taking action based on } \\
\text { data }\end{array}$ \\
\hline Drivers & The factors that influence performance \\
\hline
\end{tabular}

A consensus seems to indicate that these attributes should be quantitative and have objective values instead of subjective ones. According to Braz et al. [9], they should be straightforward and easy to understand to enable a quick identification of what is being measured and how it is being measured; practical with appropriate scales; consistent and maintain meaning over time; and clear on the objectives.

When filling these attributes with data, e.g. using software solutions, some problems related to the uncertainty of data quality may occur [10]. Sousa et al [11] presented a classification of the uncertainty components or data quality problems associated with performance measurement, detailing the design, implementation, use and review stages of performance measures. The uncertainty components of the use stage of performance measurement can be classified in three groups (Fig. 1).

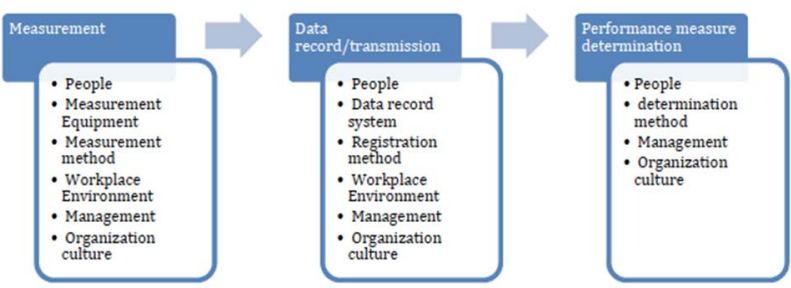

Fig. 1. Uncertainty components of performance measurement [12].
The goal of analyzing these factors is to change procedures to reduce performance measurement uncertainty. For example, "Measurement" uncertainty can be influenced by errors in the introduction and acquisition of data, like missing data and errors introduced or allowed by the data acquisition system.

BSC was implemented and extended by Grilo et al. [13], as a tool for measuring the value of interoperability among enterprises involved in a network. Regarding the studies that have documented experiences with SME in implementing the BSC Scorecard, using Excel, some studies were analysed. The main one was the book 'Balanced scorecards and operational dashboards with microsoft excel', by Person [5]. The book is fully dedicated to explaining the potential of Microsoft Excel as a tool to implement the BSC in SME. In its turn, Goriwondo et al [14] used Excel as a tool to provide graphical reporting of the implementation that they had conducted.

\section{IMPLEMMENTING THE BSC IN EXCEL}

In this section, the developed excel workbook will be discussed. The excel file comprises several worksheets. The first one is the main one, where a summary of the organization data can be analysed. The remaining sheets are used to analyse specific periods. For instance, if the organization wants to conduct monthly analysis over a period of 1 year, there should be 12 worksheets, each one analysing a month of the given year. In this example, a quarter analysis will be presented, meaning that 4 time periods, i.e., 4 time slices (TS) worksheets will be considered. These TS worksheets were named as TSx, where $x$ is the integer number that represents a time period.

This section is organized as follows: the first subsection briefly introduces the main worksheet and the second is related to the TS worksheets. The last two subsections explain the developed VBA code and how dynamic charts were included.

\section{A. Main worksheet}

At the beginning, the workbook only comprises 1 main worksheet and 1 TS worksheet. Fig. 2 depicts the information present within the main worksheet. As can be seen, the main worksheet shows several performance measures divided among the four different perspectives of the BSC. For each of these, different performance measure attributes were defined. The added attributes were adapted from [9]. The example depicted in Fig. 2 was used to track the performance indicators of the enterprise, during a year, albeit it can be easily changed to make a longer or a shorter analysis. To that end, the user only needs to respectively add or remove time slices. 


\begin{tabular}{|c|c|c|c|c|c|c|c|c|c|c|c|c|}
\hline & & & & & & & & & & Risk & indicator: & 1 \\
\hline & Year & 2017 & & & Day: & 01-10-16 & 01-01-17 & 01-04-17 & 01-07-17 & 01-10-17 & $31-12-17$ & \\
\hline NANCIAL PERSPECTIVE & eat our & Ir stakeholders? & & & & & & & & & & \\
\hline Objective & Units & s Responsible & $\begin{array}{l}\text { Measuring } \\
\text { frequency }\end{array}$ & $\begin{array}{c}\text { Revision } \\
\text { frequency }\end{array}$ & $\begin{array}{c}\text { Data } \\
\text { source }\end{array}$ & $\begin{array}{l}\text { Value in } \\
\text { year } n-1\end{array}$ & $\begin{array}{c}\text { Initial } \\
\text { value (TO) }\end{array}$ & T1 & $\mathrm{T} 2$ & T3 & T4 & $\begin{array}{l}\text { Annual } \\
\text { objectiv }\end{array}$ \\
\hline Turnover* & DG & Renato Serpa & Monthly & Annually & * & 0 & 0 & 1 & & & & 1560 \\
\hline Increase in profit* & DG & Renato Serpa & Monthly & Annually & * & 0 & 0 & & & 34 & & 43 \\
\hline $\begin{array}{l}\text { Reduction in average time of receiving or } \\
\text { income* }\end{array}$ & DA & Elsa Florêncio & Monthly & Annually & * & 122 & 122 & & & & & 100 \\
\hline $\begin{array}{l}\text { Increse in product value (sell } \\
\text { price/standart price*100) }\end{array}$ & DG & Renato Serpa & Quarterly & Annually & * & 0 & 90 & 87,8 & 87,8 & 93 & 87,8 & 95 \\
\hline Reduction in costs of inputs/sales* & DG & Telmo Silva & Monthly & Annually & * & 0 & 0 & 47,7 & & 17 & & 40 \\
\hline Average time of payments* & $\mathrm{DL}$ & Rui Pontes & Monthly & Annually & * & 89 & 89 & & 50 & 75 & 50 & 70 \\
\hline Reduction of average stocking time* & $\mathrm{DL}$ & Rui Pontes & Monthly & Annually & * & 0 & 120 & 69 & 69 & 100 & 69 & 95 \\
\hline
\end{tabular}

Fig. 2. Main worksheet

In this main worksheet, the user can also fill the year of the analysis - in one of the two cells with a red background, which can be seen in Fig. 2 - and the amount spacing of the risk indicator. It should also be noted that the data entered in the excel file is validated using excel validation, to ensure the quality if the input data. This last input is a measure that gives the extent of the risk indicator shown in the sheets related to quarters data. Afterwards, the user must fill the attributes of the performance indicators such as objective, unit, the initial values and the annual objectives - cells with the white background. After filling the initial worksheet with this initial data, the user will be able to start filling the remaining ones.

\section{B. TS Worksheets}

At this point, the user should start filling the worksheet correspondent to the first time period - TS1. Fig. 3 illustrated the heading of TS worksheets.

As can be seen, the user should insert the number 1 in the cell with the red background - this cell will later be used to save the data to the main worksheet in the proper order. Afterwards, the remaining cells - initial data of the analysis, the finish data, current data, the number of days of the total period of analysis, as well as the number of days of the time slot in question - will be calculated through excel formulas and functions.

Thereafter, the user can proceed with the input of the data related to the time period in analysis. Fig. 4 shows the performance indicators of the internal process dimension of the BSC of worksheet TS1. After ensuring the correctness of the TS1 sheet, it must be duplicated in the process of generating of the remaining TS worksheets - in this example TS2, TS3 and TS4. Each of these sheets will serve one of the 4 quarters (T1, T2, T3 and T4) in the main worksheet (depicted in Fig. 2). Moreover, with the right introduction of the integers representing the order of the TS worksheets, it is ensured that the values taken to the main worksheet will be properly set, through the use of VBA (the explanation of this VBA code will be addressed in the next subsection). For instance, for the second quarter, the value to enter must be 2 and so on, for the remaining sheets. This way, in the main worksheet, the columns T1 to T4 will receive and save these values, so that these columns become a record of observations, to provide future analysis and better estimate future missing values.

The process of filling in the TS worksheets with the data of the organization is similar to the process of filling in the main worksheet - the user has to fill the cells with the white background. Thus, for each performance indicator, the user must fill in the real value and point out the type of reading. In this last indicator, the user will only be allowed to choose among three types of inputs: real value, last value; or forecast. If the set value is real value, it will be considered for analysis.

On the other hand, if the specified value is 'last value', as the name implies, the worksheet will refer to the last known value - in previous observations - at the main worksheet. To warn the user about this possible not fully accurate register, in this case, the column 'help' - at the right of the 'type of reading' column - will show the value correspondent to the last measure. Additionally, the temporal distance from the present time to the date of this value is saved in an auxiliary column, located in the right zone of the sheet, to be used in future risk calculation. In its turn, if the value is to be based on historical values already known, a function that returns an estimation of this value will be used. This estimation reliability increases with the number of past known values. In both cases, after choosing the reading type, the worksheet does not set the value in the real value cell. But rather displays the value that results from the selection, in a help column. The user should be acquainted with this value and insert it, or another one, in the real value column. This way, the user can change the value, if he does not want to follow the suggested value from the worksheet calculations.

Apart from the actual value and type of reading, the TS worksheet also shows values for other attributes. For instance, the implementation level, the projection for today and deviation.

365 number of days of the total period

90 number of days of each time slot

Save Data

\section{Save Data}




\begin{tabular}{|c|c|c|c|c|c|c|c|c|c|c|c|c|c|}
\hline Objective & Responsible & $\begin{array}{c}\text { Value } \\
\text { year } n-1\end{array}$ & $\begin{array}{l}\text { Initial } \\
\text { value }\end{array}$ & $\begin{array}{c}\text { Annual } \\
\text { objective }\end{array}$ & $\begin{array}{c}\text { Reading } \\
\text { type }\end{array}$ & help & $\begin{array}{c}\text { Real } \\
\text { value }\end{array}$ & $\begin{array}{c}\text { Level of } \\
\text { implemmentation }\end{array}$ & Deviation & Risk & $\begin{array}{l}\text { Measuring } \\
\text { frequency }\end{array}$ & $\begin{array}{c}\text { Forecast for } \\
\text { today }\end{array}$ & $\begin{array}{c}\text { Annual } \\
\text { forecast }\end{array}$ \\
\hline 11 ISO 9001 certification & DG & 0 & 0 & 1 & Forecast & 0 & 0 & $0 \%$ & $-100 \%$ & |l|| & Quarterly & 0,2 & 0,8 \\
\hline $\begin{array}{l}\text { Increase in internal production / } \\
12 \text { production employees } \\
\text { Invoicing of internal production / } \\
\text { number of production }\end{array}$ & DP & 3440 & 3440 & 5000 & Real Value & 5450 & 5450 & $100 \%$ & $42 \%$ & $\|$ & Monthly & 3825 & 6625 \\
\hline $\begin{array}{l}13 \text { Reduction of OF hous } \\
\text { OF hours / Standart hours * } 100 \\
\text { Percentage hours of absenteeism }\end{array}$ & DP & 102 & 102 & 95 & Real Value & 96,6 & 96,6 & $77 \%$ & $4 \%$ & II & Monthly & 100 & 91 \\
\hline $\begin{array}{l}14 \text { Hours of absenteeism/ } / N^{0} \text { of } \\
\text { potential work hours }{ }^{*} 100\end{array}$ & DA & ** & 3 & 2 & Real Value & 0,4 & 0,4 & $100 \%$ & $85 \%$ & II & Quarterly & 2,8 & 0 \\
\hline
\end{tabular}

Fig. 4. Internal process dimension of TS Worksheets

The BSC works like the dials on an airplane cockpit, in the sense that they should allow one to analyse complex information at a glance [4]. One of the ways of doing so, is by using graphical and/or chromatic indicators. In this context, the worksheet shows this graphical information to allow an analysis of the level of risk associated to the type of reading that was selected. Furthermore, chromatic information - with the same colours used in the BSC - was assigned to the deviation column. To facilitate the analysis, these cells will only appear with one of three colours - red, yellow or green.

The minimum risk is when the value is actual - the colour is lighter and the trail indicator is minimal. Riskier situations involve readings based and forecasts that are based on historical data. In the worksheet, these values are displayed in slightly darker colour and greater trail.

Estimations that consider the last known value are the ones with the highest risk. In these cases, the risk is proportional to the chronological distance to the time when that last value was taken from. This distance is displayed in the auxiliary column 'temporal distance' and it determines the trails intensity and density that appears in these situations. In other words, riskier indicators are associated with darker colours and longer trails.

After having finished the analysis of one TS worksheet, the user should save the final result values for future reference and estimations. To this end, he only needs to click on a button that appears in the rightmost position of the TS worksheet header (see Fig. 3). Hence, the values of the performance indicators that were set as real values - in the reading type cell - will be saved in the main worksheet, being associated with the correct quarter and becoming available for estimations and trend analysis that could be performed in the future.

The procedure responsible to automatically store the values of a time slice in the main worksheet is designed to work with any number of time slices and not just four, as in this example. Thus, the user can even add more columns for the time slices on the main worksheet.

Afterwards, the data stored in the column that is associated with the time unit - from which the button was pressed - is deleted. This way, it will not conflict with the new data that will be recorded. The procedure only erases the values, leaving the text of the labels, identifying the time unit, completely unchanged.

In the next step, the values from the time slice are read and stored in the main worksheet. It should be noted that the data resulting from estimations or the last known values (in both cases, derived from the lack of known real values) are not saved. To assess this, and only save the relevant values, the procedure queries the value stored in the reading type column, to evaluate whether this is an actual value or not. Lastly, the procedure gives information to the user, through a message box, saying that it has completed its task of saving the data in the main worksheet.

The dynamic charts feature will enable managers to analyse possible relations that may exist between two or more performance measures. These possible relations may not be obvious and, sometimes, they can only be discovered some time periods after their occurrences, due to lag effects. To do this analysis excel dynamic charts are used. In the main worksheet, the range of data was selected for one of the four organization perspectives. This way, whenever the user wants to create a new chart, he only needs to drag and drop - and sometimes edit some minor properties - in order to visualize a chart, which is automatically created. Fig. 5 shows an example of a chart that was dynamically created.

As can be seen, it is possible to compare different performance measures of the organization, even through different TC. This way, conclusions can be withdrawn by establishing comparisons among these performance measurements.

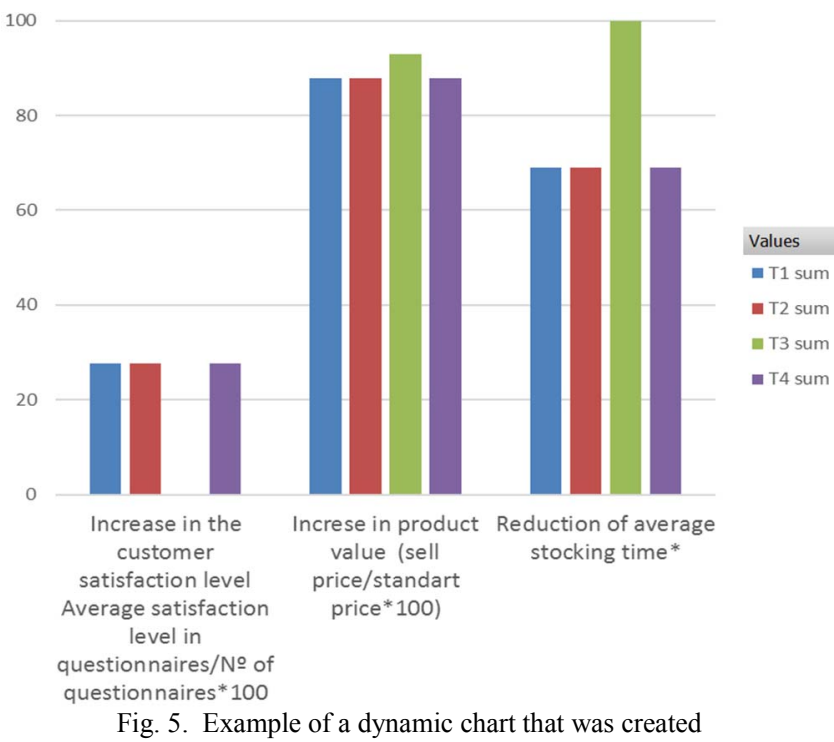

Fig. 5. Example of a dynamic chart that was created 


\section{CONCLUSION}

In this paper, the work conducted on an excel file to implement a BSC framework was presented. This way, SME can use a low cost solution, to measure their processes' performance. The main requirement is that the excel file must comply with the main characteristics of a good performance measure and, additionally, provide good ways to classify the uncertainty components of data quality. Furthermore, it should also comply with the characteristics of the BSC, enabling users to evaluate complex data at a glance and considering multi-dimension perspectives over the four different activities of an organization, as well as its strategy.

The developed file will allow SME to implement the BSC. Features such as the ability to have a chromatic view over the data were incorporated. Moreover, the data quality was also addressed by introducing risk analysis, through the utilization of trails with different shades (darker or lighter, depending on the risk).

The remaining implemented features include VBA code to automatically save the data from TS worksheets into the main one and the ability to dynamically create charts that allow the user to relate the behaviours of different performance measures, through different time periods. This way, the user does not need to create charts, he only needs to drag and drop what he desires to analyse to the right place and the chart will be generated.

Workgroup sessions of organizations are also possible with the developed tool, albeit online platforms still do not allow the use of VBA code to run on the cloud, as well as dynamic charts to be managed. Therefore, the workbook would have to be used without the implemented feature to automatically save the data from TS worksheets to the main worksheet.

The implemented features can support managers' decisions and actions, by using this, or a similar tool.

\section{ACKNOWLEDGMENT}

This work has been supported by COMPETE: POCI01-0145-FEDER-007043 and FCT - Fundação para a Ciência e Tecnologia within the Project Scope: UID/CEC/00319/2013.

\section{REFERENCES}

[1] S. S. Nudurupati, U. S. Bititci, V. Kumar, and F. T. Chan, "State of the art literature review on performance measurement," Computers \& Industrial Engineering, vol. 60, no. 2, pp. 279-290, 2011.

[2] A. Neely, M. Gregory, and K. Platts, "Performance measurement system design: A literature review and research agenda," International journal of operations \& production management, vol. 25, no. 12, pp. 1228-1263, 2005.

[3] A. Neely et al., "Performance measurement system design: developing and testing a process-based approach,"
International Journal of Operations \& Production Management, vol. 20, no. 10, pp. 1119-1145, 2000.

[4] R. Kaplan and D. Norton "The balanced scorecard measures that drive performance," Harvard Business Review, pp. 71-79, 1992.

[5] R. Person, Balanced scorecards and operational dashboards with microsoft excel. John Wiley \& Sons, 2013.

[6] S. D. Sousa, E. M. Aspinwall, and A. G. Rodrigues, "Performance measures in English small and medium enterprises: Survey results," Benchmarking - an International Journal, vol. 13, no. 1-2, pp. 120-134, 2006.

[7] A. Shamsuzzoha, T. Kankaanpää, L. Carneiro, and P. T. Helo, "Implementation framework for collaboration in a non-hierarchical business network," in IEEE International Conference on Industrial Engineering and Engineering Management (IEEM), 2010, pp. 2254-2258.

[8] S. Sousa and E. Aspinwall, "Development of a performance measurement framework for SMEs," Total Quality Management and Business Excellence, vol. 21, no. 5, pp. 475-501, 2010.

[9] R. G. F. Braz, L. F. Scavarda, and R. A. Martins, "Reviewing and improving performance measurement systems: An action research," International Journal of Production Economics, vol. 133, no. 2, pp. 751-760, 2011.

[10] A. Meekings, S. Povey, and A. Neely, "Performance plumbing: installing performance management systems to deliver lasting value," Measuring Business Excellence, vol. 13, no. 3, pp. 13-19, 2009.

[11] S. D. Sousa, E. P. Nunes, and I. S. Lopes, "Uncertainty Characterization of Performance Measure: A Fuzzy Logic Approach," in Transactions on Engineering Technologies: Springer, 2015, pp. 485-499, 2015.

[12] I. S. Lopes, S. D. Sousa, and E. Nunes, "Methodology for uncertainty characterization of performance measures," International Journal of Quality \& Reliability Management, vol. 33, no. 9, pp. 1346-1363, 2016.

[13] A. Grilo, R. Jardim-Goncalves, and V. Cruz-Machado, "A framework for measuring value in business interoperability," in IEEE International Conference on Industrial Engineering and Engineering Management, 2007, pp. 520-524.

[14] W. M. Goriwondo, N. Gwangwava, and S. Mhlanga, "Implementation of a Computerized Balanced Scorecard (BSC) System in a Manufacturing Organisation in Zimbabwe," International Journal of Soft Computing and Engineering (IJSCE), vol. 2 no. 6, pp. 236-240, 2013. 